Pesquisa e Reflexão em Educação Básica

\title{
A representação do negro em um livro didático de Sociologia: análise após a implementação da Lei $n^{\circ} 10.639 / 2003$
}

\author{
Rodrigo Bravin* \\ Yamilia de Paula Siqueira** \\ Larissa Franco de M. A. Pinheiro*** \\ Hiran Pinel ${ }^{* * * *}$
}

\begin{abstract}
Resumo:
Objetiva construir um diagnóstico sobre a forma como a história e cultura africana e afro-brasileira são representadas em um livro didático de Sociologia, distribuído pelo Ministério da Educação por meio do Programa Nacional do Livro Didático (PNLD). O foco direcionou-se para as representações imagéticas e textuais presentes no livro, para analisá-las à luz da Lei no 10.639/2003 que tornou obrigatório o estudo da história e cultura afro-brasileira nos estabelecimentos de Ensino Fundamental e Médio brasileiro e, nesse caso, elegemos o livro didático: Sociologia para Jovens do Século XXI (2013) que foi escolhido pelos professores da escola no PNLD de 2015 entre seis opções disponíveis. A obra pesquisada está de acordo com Lei no 10.639/2003 e com os preceitos estabelecidos na proposta de educação para as relações étnico-raciais. Porém, por atender um programa nacional, não abarca regionalidades, especificidades e questões locais da população negra do Espírito Santo como, por exemplo, as Comunidades Tradicionais Quilombolas que estão em várias partes do território estadual. Nesse sentido, reforçamos a necessidade de a Secretaria de Estado da Educação (SEDU) produzir materiais complementares e ofertar formação continuada para os educadores da rede, focados no povo negro capixaba.
\end{abstract}

\section{Palavras-chave:}

Educação. Livro didático. Sociologia. Representações. Lei n 10.639/2003.

\footnotetext{
* Cientista social, mestre e doutorando em Educação pelo PPGE/UFES e professor de Sociologia da rede estadual de educação do Espírito Santo. Membro do Grupo de Pesquisa em Fenomenologia, Educação Especial e Inclusão (GRUFEI). E-mail: rodrigobravin@gmail.com. ORCID iD: https://orcid.org/0000-0002-2661-3513.

** Cientista social, mestranda profissional em Educação pela Universidade Federal do Espírito Santo (UFES) e professora de Sociologia na rede estadual do Espírito Santo. E-mail: yamilia.siqueira@gmail.com. ORCID iD: https://orcid.org/0000-0002-7853-0090. *** Mestra em Ciências Sociais (UFES) e mestra em Ensino de Humanidades (IFES). Doutoranda em Educação (UFES). Participa do grupo de pesquisa Infância, Educação, Sociedade e Cultura (IESC). E-mail: Iarissafma@gmail.com. ORCID iD: https://orcid.org/0000-0002-1568-6370.

**** Psicólogo, professor doutor titular da Universidade Federal do Espírito Santo (UFES) e coordenador do Grupo de Pesquisa em Fenomenologia, Educação Especial e Inclusão (GRUFEI). E-mail: hiranpinel@gmail.com. ORCID iD: https://orcid.org/0000-0002-8540-6653.
} 


\section{Resumen:}

Tiene como objetivo construir un diagnóstico de cómo la historia y la cultura africana y afrobrasileña están representadas en un libro de texto de Sociología, distribuido por el Ministerio de Educación a través del Programa Nacional de Libros de Texto (PNLD). El foco se dirigió a las representaciones imaginarias y textuales presentes en el libro, para analizarlas a la luz de la Ley no 10.639/2003, que hizo obligatorio el estudio de la historia y la cultura afrobrasileña en los establecimientos de la escuela primaria y secundaria brasileña. En este caso, elegimos el libro de texto: Sociología para jovens do século XXI (2013), que fue elegido por los docentes de la escuela en el PNLD 2015 entre seis opciones disponibles. El trabajo investigado está de acuerdo con la Ley no 10.639/2003 y con los preceptos establecidos en la propuesta de educación para las relaciones étnico-raciales. Sin embargo, al ser un programa nacional, no cubre regionalidades, especificidades y problemáticas locales de la población negra de Espírito Santo, como por ejemplo, las Comunidades Tradicionales Quilombolas que se encuentran en diversas partes del territorio estatal. En este sentido, reforzamos la necesidad de que la Secretaría de Educación del Estado (SEDU) produzca materiales complementarios y ofrezca capacitación permanente a los educadores en red, enfocados a la población negra de Espírito Santo.

\section{Palabras-clave:}

Educación. Libro de texto. Sociología. Representaciones. Ley nº10.639/2003.

\section{Introdução}

O objetivo deste trabalho foi construir um diagnóstico sobre a forma como a história e cultura africana e afro-brasileira são representadas em um livro didático de Sociologia, distribuído pelo Ministério da Educação por meio do Programa Nacional do Livro Didático (PNLD). O foco direcionou-se para as representações imagéticas e textuais presentes no livro, para analisá-las à luz da Lei $n^{\circ} 10.639$ (BRASIL, 2003) que tornou obrigatório o estudo da história e cultura afro-brasileira nos estabelecimentos de Ensino Fundamental e Médio públicos e privados.

As imagens são recursos importantes que possibilitam a representação de ideias, valores, normas, dentre outras possibilidades. Por isso, estão presentes em quase todos os livros didáticos utilizados na educação básica, oferecendo possibilidades pedagógicas de aprendizagem e fixação de conceitos, e ainda de avaliação da forma como os diversos conteúdos são representados, além das perspectivas políticas presentes.

Nossa experiência em sala de aula nos permite afirmar que, em geral, os livros didáticos apresentam limitações que precisam ser objeto de reflexão. Sobre a história e cultura afro-brasileira, por exemplo, Silva (2005) afirma que o negro é mostrado em materiais pedagógicos e nos meios de comunicação de forma caricatural, folclorizada, estereotipada e sem humanidade.

Ao mesmo tempo, os livros didáticos são em muitos casos, os materiais pedagógicos mais utilizados por escolas, professores e estudantes e, por isso, desempenham um papel importante na formação de opinião da juventude. Nesse sentido, Silva (2005, p. 23) enfatiza que "para as crianças empobrecidas, esse livro ainda é, talvez, o único recurso de leitura na sua casa, onde não se compram jornais e revistas”.

O Plano Nacional de Implementação das Diretrizes Curriculares Nacionais para Educação das Relações Étnico-Raciais e para o Ensino de História e Cultura Afro-Brasileira e Africana (BRASIL, 2013) orienta que coordenadores pedagógicos, orientadores educacionais, professores façam uma revisão crítica das representações dos negros nos textos, materiais didáticos, assim como tomem providências para corrigi-las.

Atendendo ao disposto no art. 26-A da Lei no 9.394 (BRASIL, 1996) - Diretrizes e Bases da Educação Nacional, o conteúdo programático desses livros e materiais didáticos deverão caracterizar a formação da população brasileira, a partir do estudo da história da África e dos africanos, a luta dos negros, a cultura negra e o negro na formação da sociedade nacional, resgatando as suas contribuições nas áreas social, econômica e política, pertinentes à história do Brasil. 
A partir da inserção obrigatória da Sociologia no currículo escolar no ano de 2009, a disciplina foi incluída pela primeira vez, em 2011, no PNLD. Por isso, ainda hoje não existem muitos livros de Sociologia ou mesmo materiais didáticos devido a essa recente introdução como disciplina obrigatória no Ensino Médio. Assim, este trabalho se torna uma importante ferramenta para os licenciados em Ciências Sociais e para outros profissionais que ministram aulas de Sociologia na medida em que permite analisar criticamente os materiais pedagógicos utilizados em sala de aula.

\title{
Referencial teórico
}

Debates sobre raça no Brasil têm se tornado cada vez mais frequentes e a sociedade tem entrado em contato com questões como cor da pele, cotas, preconceito, racismo e desigualdade racial que são mostradas em filmes, novelas, jornais, entre outros. Esse vendaval de informações, em muitos casos, contribui para a internalização de diversos equívocos referentes à população negra desse país. A situação de exclusão e abandono que milhares de negros e negras do Brasil vivenciam, vem sendo construída há mais de quinhentos anos e ainda hoje não é tratada com a devida importância pelo poder público.

\begin{abstract}
A linguagem é uma das manifestações mais próprias de uma cultura. Longe de ser apenas um veículo de comunicação objetiva, ela dá testemunho das experiências acumuladas por um povo, de sua memória coletiva, seus valores. A linguagem não é só denotação, é também conotação. Nos meandros das palavras, das formas usuais de expressão, até mesmo nas figuras de linguagem, frequentemente alojam-se, insidiosos, o preconceito e a atitude discriminatória. Há palavras que fazem sofrer, porque se transformaram em códigos do ódio e da intolerância. (CARDOSO, 2005, p. 7).
\end{abstract}

Dentro desse contexto está a escola, que cumpre um papel importante na sociedade, pois é responsável por construir conhecimentos, comportamentos e opiniões. Essa instituição tem o poder de influenciar de forma positiva seus alunos, mas também negativamente, dependendo da orientação política e da forma como as práticas pedagógicas ocorrem. Tendo em vista que no espaço escolar são socializados diariamente conceitos e valores, como por exemplo, o racismo, entendemos que os professores precisam compreender seu papel na formação de meninos e meninas.

Anjos (2005, p. 174-175) lembra que:

\begin{abstract}
Não podemos perder de vista que entre os principais entraves ao desempenho do negro brasileiro na sociedade brasileira destaca-se a inferiorização deste na escola. A raiz dessa desigualdade secular estaria localizada na pré-escola. O sistema escolar tem sido estruturado para a perpetuação de uma ideologia sócio-político-econômica que, junto com os meios de comunicação social, mantém uma estrutura classista, transmissora de valores distorcidos e individualistas [...].
\end{abstract}

O racismo se constitui até os dias de hoje como um grave problema no mundo e, por isso, o ambiente escolar não está imune à suas consequências. Nesse sentido, cabe questionar qual o papel da escola? Freire (1996) ensina que escola e educadores devem respeitar os estudantes e considerar os saberes que eles trazem, inclusive para usá-los no trabalho pedagógico. Assim, é provável que os educandos já tenham vivenciado situações de racismo e/ou tomado conhecimento por meio de contatos pessoais, televisão, internet e jornais. Essas experiências podem ser o ponto de partida para a construção de momentos profundos de reflexão, aprendizagem e cidadania. Freire (1996, p. 30) colabora com o debate afirmando: 
Por que não discutir com os alunos a realidade concreta a que se deva associar a disciplina cujo conteúdo se ensina, a realidade agressiva em que a violência é a constante e a convivência das pessoas é muito maior com a morte do que com a vida? Por que não estabelecer uma 'intimidade' entre os saberes curriculares fundamentais aos alunos e a experiência social que eles têm como indivíduos? Por que não discutir as implicações política e ideológicas de um tal descaso dos dominantes pelas áreas pobres da cidade?

De acordo com a Lei no 11.645 (BRASIL, 2008), o estudo da História e Cultura Afro-Brasileira e Indígena na formação do povo brasileiro torna-se obrigatórios no currículo escolar. Essa norma passou a valer para todos os níveis da educação básica com a instituição das Diretrizes Curriculares Nacionais para a Educação das Relações Étnico-Raciais. Por isso, pensar a escola como um espaço de formação que está inserido num processo mais amplo exige uma mudança de paradigma que supere a ideia centrada em currículos, disciplinas escolares, regimentos, normas, provas, teste, conteúdos. Que reconheça que suas ações pedagógicas têm poder de interferir de forma contundente na construção da identidade dos estudantes.

Freire (1996) sinalizava, por meio de uma série de razões históricas, que um dos grandes problemas de nossa educação é a inexperiência democrática e a centralidade na palavra, no verbo, nos programas e no discurso. Nesse sentido, a educação é socialmente determinada, ou seja, a prática educativa e especialmente os objetivos e conteúdos de ensino estão determinados por fins e exigências sociais, políticas e ideológicas.

Uma barreira apontada por Munanga (2005, p. 15) é a dificuldade que muitos professores têm de utilizar situações de preconceito de forma pedagógica já que boa parte de nossos instrumentos de trabalho "isto é, livros e outros materiais didáticos visuais a audiovisuais carregam os mesmos conteúdos depreciativos e preconceituosos em relação aos povos e culturas não oriundos do mundo ocidental [...]".

Além disso, esse mesmo autor aponta a fragilidade na formação pessoal e profissional de muitos professores e educadores, que é agravada pelo fato de vivermos em um país que ignora sua própria história escravocrata e racista ao afirmar que aqui todos são iguais e têm as mesmas oportunidades.

Alguns dentre nós não receberam na sua educação e formação de cidadãos, de professores e educadores o necessário preparo para lidar com o desafio que a problemática da convivência com a diversidade e as manifestações de discriminação dela resultadas colocam quotidianamente na nossa vida profissional. Essa falta de preparo, que devemos considerar como reflexo do nosso mito de democracia racial, compromete, sem dúvida, o objetivo fundamental da nossa missão no processo de formação dos futuros cidadãos responsáveis de amanhã [...]. (MUNANGA, 2005, p. 15).

Freire (1996) oferece como proposta a busca pela igualdade apostando numa educação fundada no diálogo como necessidade existencial, e na qual todos têm direito à voz e se educam mutuamente. Este diálogo promove uma reflexão que pode conduzir qualquer indivíduo a um nível crítico elevado, possibilitando reflexão e emancipação.

Gomes (2003, p. 4) mostra que "o olhar lançado sobre o negro e sua cultura, na escola, tanto pode valorizar identidades e diferenças quanto pode estigmatizá-las, discriminá-las, segregá-las e até mesmo negá-las". Para entender melhor, qualquer ação que implique em exclusão, distinção, restrição ou preferência baseada na raça, cor e nacionalidade é considerada como discriminação racial.

Construir uma identidade negra positiva em uma sociedade que, historicamente, ensina ao negro, desde muito cedo, que para ser aceito é preciso negar-se a si mesmo, é um desafio enfrentado pelos negros brasileiros. Será que, na escola, estamos atentos a essa questão? Será que incorporamos essa realidade de maneira séria e responsável quando discutimos, nos processos de formação de professores, sobre a importância da diversidade cultural? (GOMES, 2003, p. 3).

Entende-se que um dos caminhos para a construção de práticas formadoras que eduquem para a diversidade poderá ser um olhar mais atento aos caminhos e percurso dos estudantes. Sabe-se que é essencial 
e principal de toda escola promover e desenvolver a aprendizagem do indivíduo nas diferentes dimensões: sociais, cognitivas, emocionais e motoras. Gomes (2003) nos ensina que é na cultura e na história que definimos as identidades e os preconceitos sociais.

Nesse sentido, a escola deve ser local de diálogo, de aprender a conviver, vivenciando a própria cultura e respeitando as diferentes formas de expressão cultural, de ampliar o horizonte de referências do aluno, despertando a curiosidade epistemológica (FREIRE, 1996).

Recuperar as origens dessas influências é valorizar os povos que as trouxeram e seus descendentes, reconhecendo suas lutas pela defesa de dignidade e da liberdade, atuando na construção cotidiana do Brasil, dando voz a um passado que se faz presente em seres humanos que afirmam sua dignidade na herança cultural que carregam. É também reconhecer a grande dívida que o Estado brasileiro tem com todos esses povos que foram trazidos de diversos países africanos e escravizados aqui, bem como perceber a importância do negro na construção do Brasil.

\section{Metodologia, apresentação e análise dos resultados}

Para responder ao objetivo proposto nesta pesquisa utilizou-se como técnica de análise dos dados a análise de conteúdo que é definida por Bardin (2009, p. 38) como,

[...] um conjunto de técnicas de análise das comunicações visando a obter, por procedimentos sistemáticos e objetivos de descrição do conteúdo das mensagens, indicadores, (quantitativos ou não) que permitam a inferência de conhecimentos relativos às condições de produção/recepção (variáveis inferidas) dessas mensagens $[\ldots]$.

O enfoque da pesquisa se baseou no materialismo dialético, já que se buscou uma visão de totalidade para compreensão não somente do livro didático em si, mas, também, das implicações sociais e educacionais das representações textuais e imagéticas sobre a população negra na formação dos estudantes. Triviños (1987), ao recomendar o emprego desse método, salienta que ele se torna necessário para a análise das motivações, valores, crenças e também para elucidar ideologias que podem passar despercebidas nos princípios, dispositivos legais e diretrizes. "O Materialismo Dialético sustenta como Critério da Verdade a Prática Social [...]” (TRIVIÑOS, 1987, p. 27).

Após uma triagem inicial dos livros de sociologia utilizados em escolas estaduais do Espírito Santo, optou-se pela obra Sociologia para Jovens do Século XXI, de autoria de Luiz Fernandes de Oliveira e Ricardo Cesar Rocha da Costa (2013), da editora Imperial Novo Milênio, que possuiu 399 páginas, com o exemplar do professor contendo 96 a mais, pois agrega exercícios e orientações gerais. Essa obra fez parte do Programa Nacional do Livro Didático (PNLD) de 2015 junto com outros cinco livros e foi adotado pelos professores da escola na qual duas autoras desta pesquisa fizeram estágio docência (Figura 1).

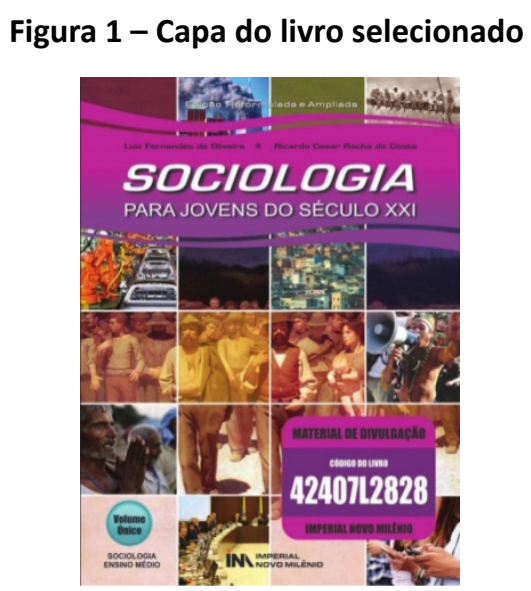

Fonte: Oliveira e Costa (2013). 
Os procedimentos empregados para construção do trabalho foram a pesquisa documental no livro didático e a análise da Lei no 10.639, de 09 de janeiro de 2003 para conhecimento acerca do tema, além do levantamento de referencial teórico para fundamentar as análises.

O livro Sociologia para Jovens do Século XXI traz uma abordagem variada e interessante dentro do que se espera do tema da educação das relações étnico-raciais. Em vários momentos insere dentro dos capítulos a temática de forma muito atual e inovadora. Ultrapassa visões simplistas, gerais e distorcidas, geralmente baseadas em senso comum, e se aprofunda na discussão, inclusive com apresentação de dados atualizados baseados em pesquisas realizadas pelo Instituto Brasileiro de Geografia e Estatística (IBGE) e Instituto de Pesquisa Econômica Aplicada (IPEA). Sem contar que utiliza autores reconhecidos como Kabengele Munanga e Gilberto Freyre para explicar os assuntos, o que dá uma profundidade na explicação dos tópicos.

Identificamos de maneira geral que ao longo da obra os autores utilizam formas variadas de abordar as questões raciais. Em alguns momentos fazem uma problematização mais elaborada e em outros falam de forma direta. Consideramos pertinente diversificar as práticas pedagógicas, pois possibilitam estimular os vários sentidos dos estudantes no processo de aprendizagem. A educação para as relações étnico-raciais é um campo amplo e se conecta com várias outras temáticas como cultura, identidade, desigualdade etc. Nesse sentido, a obra pesquisada trás as questões raciais em quase todos os capítulos o que é um ponto positivo. A seguir elencamos as principais contribuições encontradas no processo de análise do livro didático. Gomes (2005, p. 146) enfatiza que:

Ainda encontramos muitos(as) educadores(as) que pensam que discutir sobre relações raciais não é tarefa da educação. É um dever dos militantes políticos, dos sociólogos e antropólogos. Tal argumento demonstra uma total incompreensão sobre a formação histórica e cultural da sociedade brasileira. E, ainda mais, essa afirmação traz de maneira implícita a ideia de que não é da competência da escola discutir sobre temáticas que fazem parte do nosso complexo processo de formação humana. Demonstra, também, a crença de que a função da escola está reduzida à transmissão dos conteúdos historicamente acumulados, como se estes pudessem ser trabalhados de maneira desvinculada da realidade social brasileira.

Nos capítulos iniciais (de 1 a 3) do livro, como por exemplo, no terceiro "O que se vê mais, o jogo ou o jogador: indivíduos e instituições sociais” percebemos que mesmo sem fazer menção direta ao negro são mostradas fotos e imagens apresentando personalidades importantes. Ao fazer menção às instituições sociais tais como o poder judiciário, foi utilizada uma foto do ex-ministro Joaquim Barbosa, em que o aluno pode reconhecer a imagem de um representante negro em uma importante posição no Supremo Tribunal Federal (STF).

No capítulo 4 “Torre de Babel: culturas e sociedades”, além de apresentar imagens contendo o protagonismo negro, faz referência a um provérbio nagô-iorubá de uma sociedade africana milenar localizada na Nigéria que destaca as diferenças entre os dedos, mas que por estarem na mesma mão precisam viver juntos. Umas das interpretações feitas pelos autores é necessidade de os seres humanos reconhecerem suas singularidades e promoverem o respeito mútuo: “[...] todos os seres humanos precisam se respeitar e saber conviver entre si” (OLIVEIRA; COSTA, 2013, p. 69).

Percebe-se que nos capítulos iniciais do livro os autores tratam as questões étnico-raciais de forma introdutória, reconhecendo o racismo como uma forma de desigualdade social, além de apresentarem, também, argumentos positivos sobre a presença da população negra na sociedade brasileira. Essa abordagem colabora para a desconstrução de posturas e práticas racistas, que se mantiveram quase intocáveis durante séculos e que, infelizmente, são assumidas, ainda hoje, por muitos brasileiros.

Estas práticas racistas manifestam-se, também, nos livros didáticos tanto na presença de personagens negros com imagens deturpadas e estereotipadas quanto na ausência da história positiva do povo negro no Brasil. Manifestam-se também na mídia (propagandas, publicidade, novelas) a qual insiste em retratar os negros, e outros grupos étnico/raciais que vivem uma história de exclusão, de maneira indevida e equivocada. (GOMES, 2005, p. 53). 
O capítulo-chave do livro é o de número 17 "Onde você esconde seu racismo? Desnaturalizando as desigualdades raciais", que trata do racismo e os autores fazem um trabalho de desconstrução das desigualdades raciais. Logo de entrada trazem uma imagem da KuKluxKlan ${ }^{1}$, já como um exemplo de racismo nos EUA que permanece até os dias de hoje - o que causa importante impacto (Figura 2).

Esse grupo tem sua origem, nos Estados Unidos, no século XIX e seu principal objetivo era, e ainda é, perseguir principalmente negros, mas também, posteriormente, imigrantes, judeus e defensores dos direitos da população afro-americana. São conhecidos por usarem roupas brancas, capuzes, tochas acesas, terem como símbolo uma cruz e promoverem espancamentos, agressões e enforcamento de pessoas negras. Defendem a superioridade branca e são contra qualquer ação ou lei que promova a igualdade racial.

\section{Figura 2 - Movimento supremacista branco Ku Klux Klan}

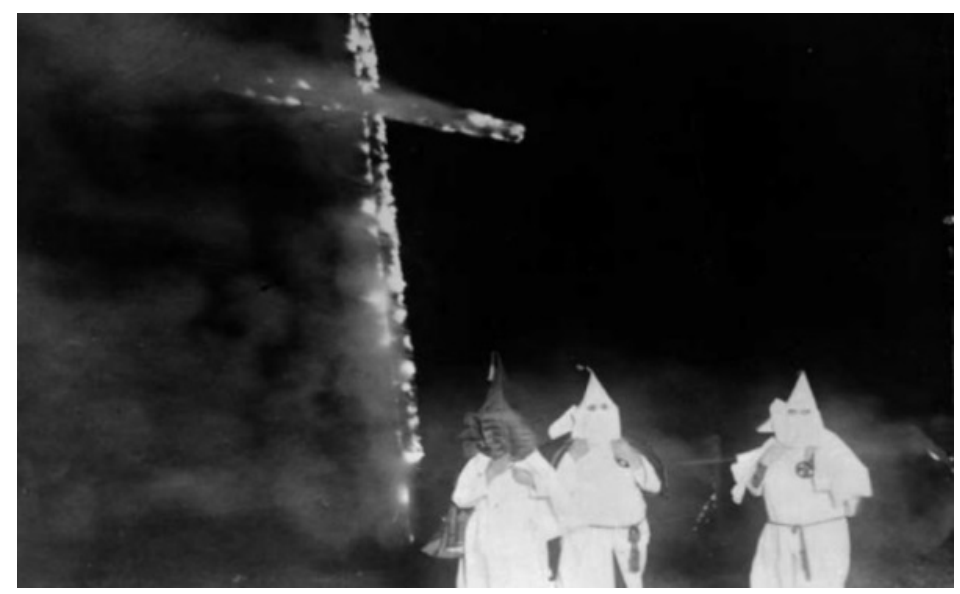

Fonte: Oliveira e Costa (2013, p. 266).

A seguir mostram exemplos brasileiros envolvendo preconceito e racismo. Os autores elaboraram uma espécie de glossário onde colocam as palavras: preconceito; discriminação e racismo que auxiliam a compreensão dos alunos e também trazem o conceito de etnia ou etnicidade. Nesse trecho inserem a imagem de uma manifestação cultural em frente a um monumento construído que homenageia Zumbi dos Palmares, para explicar que o conceito de etnicidade diz respeito a um tipo de solidariedade particular, laços intelectuais de língua e cultura, no Rio de Janeiro.

Os autores tratam do racismo, preconceito e discriminação no cotidiano brasileiro, inclusive, das várias ideias pré-concebidas e sem fundamentação, que colocam o negro como naturalmente inferior ao branco, ocupando o imaginário coletivo nacional. Outro acerto do livro foi a preocupação em valorizar a África, corrigindo distorções e enfatizando-a como um continente composto por vários países, povos e culturas.

A África é valorizada como o local de surgimento da humanidade e onde se desenvolveram as primeiras técnicas de metalurgia, de fundição de metais, de escrita, de cálculos matemáticos, de engenharia e de comércio internacional. Há também uma exaltação às grandes construções arquitetônicas africanas, às navegações em alto-mar, ao comércio internacional e troca de mercadorias com o extremo Oriente. Essa forma de abordar a África está de acordo com o que determina as Diretrizes Curriculares Nacionais para a Educação das Relações Étnico-Raciais e para o Ensino de História e Cultura Afro-Brasileira e Africana (BRASIL, 2004).

A obra traz uma importante reflexão sobre o processo de miscigenação ocorrido no Brasil e a teoria do branqueamento (eugenia), junto de uma política imigratória europeia incentivada pelo Estado brasileiro. Posteriormente, invoca o livro Casa Grande \& Senzala de Gilberto Freyre (2001), publicado em 1933 - momento em que ocorreu uma mudança no pensamento sobre o caráter das relações raciais existentes no Brasil -, em que se via a ascensão do fascismo e do nazismo na Europa.

1. Nome de várias organizações racistas dos Estados Unidos que apoiavam e ainda apoiam a supremacia branca e o protestantismo em detrimento de outras religiões, com maior atuação no Texas e no Mississipi. 
Para Silva (2005, p. 23):

A ideologia do branqueamento se efetiva no momento em que, internalizando uma imagem negativa de si próprio e uma imagem positiva do outro, o indivíduo estigmatizado tende a se rejeitar, a não se estimar e a procurar aproximar-se em tudo do indivíduo estereotipado positivamente e dos seus valores, tidos como bons e perfeitos.

Os autores utilizam trabalhos do congolês Kabengele Munanga, importante professor e pesquisador de questões raciais no Brasil, para explicar que o discurso da mestiçagem foi uma estratégia inteligente das elites para evitar o aparecimento explícito do racismo e garantir a dominação cultural branca europeia. O livro também referência Florestan Fernandes, sociólogo brasileiro que foi um grande crítico do mito da democracia racial brasileira ${ }^{2}$.

Fernandes (1989) afirmava que os mitos são criados para esconder a realidade. No caso brasileiro, o autor explica que a miscigenação serviu como argumento para afirmar o Brasil como um país democrático e com oportunidades para todos. Mas, na prática, a população negra foi abandonada à própria sorte após a abolição e a propagação desse mito pavimentou a construção de um racismo "à brasileira" dissimulado e que dificultava o questionamento.

Sobre isso, o autor reforça que:

\begin{abstract}
A democracia só será uma realidade quando houver, de fato, igualdade racial no Brasil e o negro não sofrer nenhuma espécie de discriminação, de preconceito, de estigmatização e de segregação seja em termos de classe, seja em termos de raça. Por isso, a luta de classes, para o negro, deve caminhar juntamente com a luta racial propriamente dita [...]. (FERNANDES, 1989, p. 43).
\end{abstract}

Ele aponta que "o brasileiro tem preconceito de ter preconceito" (OLIVEIRA; COSTA, 2013, p. 276), situação resultante da ideologia do embranquecimento e da democracia racial que faz com que muitos não admitam uma identidade étnica diferente daquela de origem europeia. Além disso, a obra apresenta pesquisa da Pesquisa de Amostras por Domicílio (PNAD) do Instituto Brasileiro de Geografia e Estatística (IBGE) de 1976 sobre a cor da pele do povo brasileiro que apontou 136 cores.

A partir desse resultado o IBGE resolveu na década de 1990 instituir cinco classificações sobre cor/“raça" do brasileiro: branca, preta, parda, amarela e indígena. Os autores explicam o porquê de ainda se utilizar o termo raça dentro das pesquisas do IBGE (já que se trataria de um termo em desuso). Trata-se de uma forma de saber como o fenômeno do racismo afeta a população brasileira. Adiante, explicam que o termo adquire conotação política "raça negra", passando por um processo de ressignificação para representar um conjunto de indivíduos que dividem as mesmas histórias e culturas, tanto no passado como no presente.

Os autores destacam a trajetória do movimento negro no Brasil e no mundo. No capítulo 15, "Você tem fome de quê? Movimentos Sociais ontem e hoje", colocam o esse grupo como um dos principais do século XXI. Ao final do capítulo sugerem um samba “O mestre-sala dos mares”, de autoria de João Bosco e Aldir Blanc que faz referência à Revolta da Chibata ocorrida em 1910 e ao seu líder, João Cândido. Trata-se de algo muito importante, pois ilustra uma situação que certamente faz parte do movimento negro que é a resistência contra os castigos corporais que ocorriam contra marinheiros negros dentro da Marinha do Brasil, mesmo depois do término da escravidão.

De volta ao capítulo 17 sobre o racismo e a desnaturalização das desigualdades raciais, os autores abordam mais sobre o movimento negro. Nele trazem explicações sobre como se desenvolveu o movimento negro nos EUA, inclusive, a influência que exerceu sobre o movimento negro no Brasil. Abordam datas

2. Na obra Casa Grande e Senzala de Gilberto Freyre (2001), publicado na década de 30 encontramos uma história narrada a partir do que ficou conhecido como "mito da democracia racial", afinal é afirmado nesse livro, que no Brasil as "três raças" que formaram a sociedade brasileira conviviam de maneira amistosa, desde a escravidão. Compreende-se, portanto que o mito da democracia racial brasileira é uma crença de que no país não existiu e nem existe racismo e/ou discriminação racial. 
comemorativas brasileiras como o Dia Nacional de Denúncia contra o Racismo (13 de maio) e a Semana Nacional da Consciência Negra (de 18 a 22 de novembro), com destaque para 20 de novembro, dia em que se comemora a resistência e a morte do "herói nacional negro", Zumbi dos Palmares.

\section{Figura 3 - Feriado do Dia da Consciência Negra}

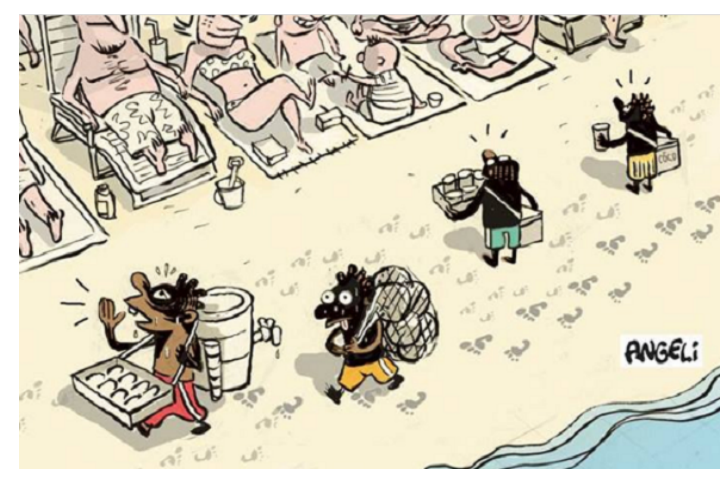

Fonte: Angeli (2006 apud OLIVEIRA; COSTA, 2013, p. 278).

Essas datas são significativas e contribuem para "a denúncia das repercussões das políticas de eliminação física e simbólica da população afro-brasileira na pós-abolição, e de divulgação dos significados da Lei Áurea para os negros” (BRASIL, 2013, p. 95). Todavia, não foi mencionado o dia 21 de março, considerado Dia Internacional pela Eliminação da Discriminação Racial ${ }^{3}$ em memória ao massacre ocorrido na África do Sul, em 1960, por conta do regime de segregação racial.

Relembrar momentos importantes como a Semana da Consciência Negra colabora para que os alunos conheçam a realidade de grande parte da população negra brasileira e também para compreensão das desigualdades sociais. Os autores trazem, posteriormente, uma charge de Angeli (2006 apud OLIVEIRA; COSTA, 2013, p. 278), que foi publicada no dia 20 de novembro de 2006 no jornal Folha de São Paulo e representa muito bem essa situação: no feriado do Dia da Consciência Negra, retratam uma praia repleta de gente, sendo que os únicos que estão trabalhando como ambulantes são os negros (Figura 3).

Também no capítulo 17 os autores situam que o termo afrodescendente surgiu nos anos de 1990 nas pesquisas do IBGE para se referir aos negros e pardos. Essa expressão teria duas finalidades para eles. A primeira é a de desenvolver "uma nova identidade positivamente afirmada, com histórias e culturas tradicionalmente herdadas ou reconstruídas de uma África ressignificada [...]”. A segunda diz respeito a uma forma de "resposta-proposta às ambiguidades classificatórias que tanto pesaram e pesam sobre os negros no Brasil e seus descendentes" (OLIVEIRA; COSTA, 2013, p. 278).

Nesse mesmo capítulo explicam a política de ações afirmativas e destacam as cotas para negros nas universidades, apresentando um quadro com argumentos a favor e contra a política de cotas. Mostram a logotipo do Movimento Negro Unificado. Na conclusão, os autores colocam a importância de se discutir o tema, inclusive expõe sobre a Lei no 10.639 - política educacional objeto desse trabalho. Por fim, apresentam uma charge na qual um homem ligado ao mundo do futebol conversa com um garoto e diz que ele não necessita estudar na universidade, pois jogar bola seria sua cota.

A aproximação das escolas com o movimento negro e este ajudando a recontar a história do negro no Brasil e na África, além de reivindicar educação por meio de lutas, teatro, manifestos, etc. pode ser uma forma de corrigir a visão que desvaloriza esses povos (SILVA, 2005).

No capítulo 19 "A gente não quer só comida... religiosidade e juventude no século XXI" enfatizam que a formação nacional se caracteriza pela influência de várias religiões, inclusive as de matrizes africanas.

3. “Em 21 de março de 1960, em Joanesburgo, na África do Sul, 20.000 pessoas faziam um protesto contra a Lei do Passe, que obrigava a população negra a portar um cartão que continha os locais onde era permitida sua circulação. Porém, mesmo tratando-se de uma manifestação pacífica, a polícia do regime de apartheid abriu fogo sobre a multidão desarmada resultando em 69 mortos e 186 feridos. Em memória a este massacre a Organização das Nações Unidas (ONU) instituiu 21 de março o dia Internacional de Luta contra a Discriminação Racial". (RÉGIA, 2014). 
Sobre as religiões no Brasil, o livro dá destaque ao candomblé e a umbanda. Em relação à primeira, ensina que os terreiros ajudaram na manutenção da herança cultural que foi passada de geração para geração. Do mesmo modo, os autores ensinam as diferenças entre Candomblé e Umbanda e trazem foto de uma procissão em referência ao Dia de Iemanjá (2 de fevereiro). Por fim, discorrem sobre o sincretismo religioso, fenômeno social que marca a religiosidade no Brasil devido à fusão de vários componentes religiosos e culturais advindos do encontro entre negros, índios e brancos. Silva (2005, p. 29) afirma que a "imposição de uma só matriz religiosa constitui-se em violência simbólica contra os grupos subordinados, que não têm poder para colocar seus conteúdos e significados culturais nos currículos de ensino das nossas escolas".

Além de apresentar a cidade como espaço urbano de segregação racial, no capítulo 20, "Espaços de dor e de esperança. A questão urbana”, os autores acrescentam que se trata também de uma segregação étnico-racial, pois as favelas são habitadas por trabalhadores com baixa ou nenhuma qualificação profissional e majoritariamente negra. Isso não acontece só no Brasil, mas também em bairros pobres da África do Sul pós-apartheid, nos guetos negros de Nova Iorque e nos bairros das principais cidades norte-americanas onde mora a classe trabalhadora de origem latina e ainda nos bairros periféricos de Paris onde residem imigrantes árabes.

Para reforçar a discussão de território, a obra busca na história do Brasil a origem da segregação socioespacial e étnico-racial, a partir do período colonial, marcado pela divisão entre casa-grande e senzala. Após a abolição e advento da república essa segregação permaneceu. Um exemplo se deu com a reforma urbana no Rio de Janeiro, onde ao mesmo tempo em que a cidade ganhava feições de modernidade, aumentavam os núcleos de favelas com o fim das áreas de cortiços que abrigavam populações pobres, principalmente negras.

Em seguida, os autores problematizam o que é a favela retratando os estigmas atribuídos a ela e seu julgamento feito de forma pré-concebida quase sempre na perspectiva da ausência. Trazem como exemplo fotos de comunidades como a da Mangueira no Rio de Janeiro.

O livro trata das favelas e da violência que ocorre dentro delas no capítulo 21 cujo título é "Chegou o caveirão. E agora? Violência e desigualdades sociais". Aprofundam o debate dos processos de criminalização que diversas comunidades são submetidas e discordam de argumentos que afirmam as favelas como espaços onde todos se envolvem com tráfico de drogas. A violência é um fenômeno complexo para ser analisado de forma simplista. Qualquer avaliação que não tenha aprofundamento incorrerá em afirmações baseadas no senso comum. Nesse sentido, um país como o Brasil que nega a cidadania para boa parte de sua população, violenta seu povo e em vários momentos o culpa por sua situação de pobreza.

Na página 340 encontramos uma figura de jovens da Zona Sul da cidade de São Paulo fazendo manifestação para denunciar a violência policial na periferia no ano de 2001. Também apresenta um dado alarmante que precisa ser considerado pelo poder público e conhecido pela sociedade: $10 \%$ do total de homicídios de jovens do planeta ocorrem no Brasil.

Para terminar, o capítulo mostra que os estudiosos da globalização e da criminalidade urbana defendem a necessidade de uma análise global desse fenômeno para não responsabilizarmos quem na verdade, muitas vezes, é vítima de um sistema econômico e social que segrega e impede o acesso aos direitos. A obra também traz dados sobre o crime organizado e dos "trabalhadores do tráfico" nas favelas nos morros cariocas que é composta por: "[...] filhos de trabalhadores, ex-trabalhadores, desempregados, meninos e meninas entre 10 e 16 anos, 'pretos', 'ou quase brancos' que ou não têm condições de ter um trabalho digno ou, quando têm, são seduzidos a ganhar mais no tráfico” (OLIVEIRA; COSTA, 2013, p. 350).

\section{Considerações finais}

A escola é um espaço de socialização e aprendizagem. Pode ser instrumento de empoderamento e reflexão ou ainda instituição onde as desigualdades são reforçadas. Nesse sentido, o Ensino Médio é um momento em que a maior parte dos jovens já desenvolveu algum grau de maturidade e, por isso, 
pode consolidar conhecimentos que garantam o exercício da cidadania ou, dependendo das práticas pedagógicas, podem tornar-se "depósitos" de conhecimento.

O livro didático é uma das ferramentas que os educadores utilizam para auxiliar no processo de ensino e aprendizagem, por isso é necessário questionar e refletir sobre os materiais que levam às salas de aula para que o ambiente escolar seja um local plural, acolhedor e respeitador de todas as diferenças.

A obra pesquisada para construção deste trabalho oferece um aprofundamento necessário sobre a questão racial, inserindo diferentes visões e propondo reflexões aprofundadas. Dentre as temáticas que são abordadas de forma satisfatória estão o preconceito e as desigualdades raciais (e sociais), a religião (com destaque para as religiões de matriz africana) e a violência urbana, especialmente contra os jovens negros de periferia.

Essas relações se expressam por meio do preconceito e se apresentam em evidências empíricas: os negros e pardos em nossa sociedade recebem, em muitas situações, salários menores e têm poucas condições de acesso a melhores condições de habitação, saúde, trabalho e cultura. Os autores enfatizam a questão do mito da democracia racial, dando destaque para pesquisadores do pensamento social brasileiro, algo de suma importância. Muitos dados oficiais do governo foram utilizados, enriquecendo e atualizando a leitura dos capítulos. Outro ponto positivo foi a grande utilização de imagens, com destaque para as charges como ferramentas pedagógicas importantes e facilitadoras da aprendizagem. Esses recursos, utilizados de forma planejada, podem estimular a reflexão, a curiosidade e aproximar os conteúdos estudados ao cotidiano dos estudantes.

De uma forma geral, o livro pesquisado atende ao que está previsto na Lei no 10.639 , e aos preceitos estabelecidos na proposta de educação para as relações étnico-raciais. Compreendendo que se trata de conteúdo introdutório voltado ao estudante do ensino médio, a obra apresenta perspectivas críticas e reflexivas, abordando vários temas no campo da educação das relações étnico-raciais. É importante salientar que, mesmo atendendo o que está previsto na legislação, a produção não apresenta dados, informações e discussões sobre a realidade do negro no estado do Espírito Santo, especialmente questões locais e regionais, assim como os demais livros de Sociologia disponíveis no mercado. Nesse caso, reconhecemos que os livros didáticos são produzidos de acordo com a Base Nacional Comum Curricular (BNCC) que é geral e visa orientar conteúdos mínimos que devem ser ensinados em todas as redes de educação.

Pontuando essa ausência, acreditamos que seria importante que a Secretaria de Estado da Educação do Espírito Santo (SEDU) em parceria com as instituições de ensino superior produzisse materiais complementares que contenham questões regionais, como por exemplo, as Comunidades Tradicionais Quilombolas e também ofertasse cursos, capacitações e formações continuadas para os educadores da rede que tenham como foco a história, cultura e a realidade da população negra capixaba.

\section{Referências}

ANJOS, Rafael Sanzio Araújo dos. A geografia, a África e os negros brasileiros. In: MUNANGA, Kabengele (org.). Superando o racismo na escola. Brasília, DF: MEC/SECADI, 2005. p. 173-183.

BARDIN, Laurence. Análise de conteúdo. Lisboa: Edições 70, 2009.

BRASIL. Diretrizes curriculares nacionais para educação das relações étnico-raciais e para o ensino de história e cultura afro-brasileira e africana. Brasília, DF: MEC/SECADI, 2004.

BRASIL. Lei no 9.394, de 20 de dezembro de 1996. Estabelece as diretrizes e bases da educação nacional. Diário Oficial da União: seção 1, Brasília, DF, p. 27.833, 23 dez. 1996.

BRASIL. Lei $n^{\circ}$ 10.639, de 6 de janeiro de 2003. Altera a Lei no 9.394, de 20 de dezembro de 1996, que estabelece as diretrizes e bases da educação nacional, para incluir no currículo oficial da Rede de Ensino a obrigatoriedade da temática "História e Cultura Afro-Brasileira", e dá outras providências. Diário Oficial da União: seção 1, Brasília, DF p. 1,10 jan. 2003.

BRASIL. Lei no 11.645. Altera a $\mathrm{n}^{\circ}$ Lei 10.639 de 10 de janeiro de 2003, de 9 de janeiro de 2003, que estabelece as diretrizes e bases da educação nacional, para incluir no currículo oficial da rede de ensino a obrigatoriedade da temática “História e Cultura Afro-Brasileira e Indígena”. Diário Oficial da União: seção 1, Brasília, DF, p. 1, 11 mar. 2008. 
BRASIL. Plano nacional de implementação das diretrizes curriculares nacionais para educação das relações étnico-raciais e para o ensino de história e cultura afro-brasileira e africana. Brasília, DF: MEC/SEPPIR, 2013.

CARDOSO, Fernando Henrique. Prefácio à 2a impressão (2000). In: MUNANGA, Kabengele (org.). Superando o racismo na escola. Brasília, DF: MEC/SECADI, 2005. p. 9-10.

FERNANDES, Florestan. Significado do protesto negro. São Paulo: Cortez, 1989.

FREIRE, Paulo. Pedagogia da autonomia: saberes necessários à prática educativa. São Paulo: Paz e Terra, 1996. (Coleção Leitura).

FREYRE, Gilberto. Casa-grande \& Senzala. 42. ed. Rio de Janeiro: Record, 2001.

GOMES, Nilma Lino. Educação, identidade negra e formação de professores/as: um olhar sobre o corpo negro e o cabelo crespo. Educação e Pesquisa, São Paulo, v. 29, n. 1, p. 167-182, jun. 2003.

GOMES, Nilma Lino. Alguns termos e conceitos presentes no debate sobre relações raciais no Brasil: uma breve discussão. In: BRASIL. Educação antirracista: caminhos abertos pela Lei Federal no 10.639/03. Brasília, DF: MEC/ SECADI, 2005. p. 39-62.

MUNANGA, Kabengele. Apresentação. In: MUNANGA, Kabengele (org.). Superando o racismo na escola. Brasília, DF: MEC/SECADI, 2005. p. 15-20.

OLIVEIRA, Luiz Fernandes de; COSTA, Ricardo Cesar Rocha da. Sociologia para Jovens do Século XXI. Rio de Janeiro: Imperial Novo Milênio, 2013.

RÉGIA, Mara. Hoje na História, 21 de Março e Dia Internacional para Eliminação da Discriminação Racial. Portal Geledés, São Paulo, 21 mar. 2014. Disponível em: https://www.geledes.org.br/hoje-na-historia-21-de-marco-e-dia-internacional-para-a-eliminacao-da-discriminacao-racial/. Acesso em: 8 ago. 2020.

SILVA, Ana Célia da. A desconstrução da discriminação no livro didático. In: MUNANGA, Kabengele (org.). Superando o racismo na escola. Brasília, DF: MEC/SECADI, 2005. p. 21-37.

TRIVIÑOS, Augusto Nibaldo Silva. Introdução à pesquisa em ciências sociais: a pesquisa qualitativa em educação. São Paulo: Atlas, 1987.

Data de submissão: 25/06/2020

Data de aceite: $16 / 08 / 2020$ 